\title{
MSH6 Nuclear Expression Intact
}

National Cancer Institute

\section{Source}

National Cancer Institute. MSH6 Nuclear Expression Intact. NCI Thesaurus. Code C160417.

An indication that expression of MSH6 was detected in the nuclei of cells in a sample. 